\title{
PERBEDAAN PENGETAHUAN PERILAKU HIDUP BERSIH DAN SEHAT SEBELUM DAN SESUDAH PENYULUHAN
}

\author{
Imroatul Azizah*, Herlinawati**
}

\begin{abstract}
ABSTRAK
Laporan hasil pendataan PHBS tatanan sekolah tahun 2012 memperlihatkan bahwa anak usia Sekolah Dasar di SDN 1 Watubelah Kabupaten Cirebon belum memiliki kebiasaan yang menunjuk perilaku hidup bersih dan sehat. Sedangkan dari pihak puskesmas sudah dilakukan penyuluhan setiap tahunnya disekolah-sekolah namun hasil dari penerapannya pada siswa disekolah masih kurang. Tujuan penelitian ini adalah untuk mengetahui perbedaan pengetahuan perilaku hidup bersih dan sehat sebelum dan sesudah penyuluhan pada siswa kelas VI di SDN 1 Watubelah Kabupaten Cirebon Tahun 2013. penelitian ini menggunakan metode pra experimen design dengan pendekatan one group pretest posttest dalam rancangan ini tidak ada kelompok pembanding (kontrol), tetapi paling tidak sudah dilakukan observasi pertama (pretest) yang memungkinkan menguji perubahanperubahan yang terjadi setelah adanya eksperimen (program). Jumlah sampel sebanyak 30 dengan menggunakan total sampling. Data diperoleh melalui kuesioner dengan wawancara. Teknik analisis penelitian ini menggunakan teknik analisis perbedaan dua perlakuan dengan uji T. Untuk pengetahuan perilaku hidup bersih siswa sebelum diberikan penyuluhan adalah pada kategori baik yaitu sebanyak 20 responden $(66,7 \%)$. Kemudian hasil penelitian yang menunjukan bahwa pengetahuan perilaku hidup bersih dan sehat siswa sesudah diberikan penyuluhan dalam kategori baik yaitu sebanyak 27 responden $(90,0 \%)$ Hasil pengujian hipotesis di peroleh nilai $\mathrm{T}$ (T test) 2.249 dan nilai sig. ( $p$-Value) 0,032.
\end{abstract}

Kata Kunci : Pengetahuan, perilaku hidup bersih dan sehat

\begin{abstract}
Report school survey results PHBS order in 2012 showed that elementary school-age children in SDN 1 Watubelah Cirebon has a habit of pointing yet clean and healthy lifestyle behaviors. While the parties have conducted outreach clinic every year in schools, but the results of its application to the school students are still lacking. The purpose of this study was to determine differences in knowledge of healthy living behaviors before and after counseling on sixth grade students at SDN 1 Watubelah Cirebon in 2013. This study uses a preexperimental design with one-group pretest-posttest approach in this design there is no comparison group (controls), but at least we have made the first observation (pretest) that allows to test the changes that occurred after the experimental (program). The total sample of 30 by using the total sampling. Data were obtained through a questionnaires with interview. this analysis technique using two different analytical techniques to test treatment $\mathrm{T}$. To the knowledge of hygienic behavior of students before giving information on both categories are as many as 20 respondents $(66.7 \%)$. Then the results of the study showed that knowledge of clean and healthy lifestyle after given counseling students in both categories as many as 27 respondents $(90.0 \%)$ in the hypothesis testing results obtained values $\mathrm{T}$ ( $\mathrm{T}$ test) and 2,249 sig. (P-value) of 0.032.
\end{abstract}

Keywords : Knowledge, clean and healthy lifestyle

\footnotetext{
* Alumni PSKM STIKes Cirebon Lulus Tahun 2014

**Staf Pengajar Program Studi S1 Kesehatan Masyarakat STIKes Cirebon
} 


\section{PENDAHULUAN}

Seiring dengan cepatnya perkembangan dalam era globalisasi, serta adanya transisi demografi dan epidemiologi penyakit, maka masalah penyakit akibat perilaku dan perubahan gaya hidup yang berkaitan dengan perilaku dan sosial budaya cenderung akan semakin kompleks. Perbaikannya tidak hanya dilakukan pada aspek pelayanan kesehatan, perbaikan pada lingkungan dan merekayasa kependudukan atau faktor keturunan, tetapi perlu memperhatikan faktor perilaku yang secara teoritis memiliki konstribusi 30 - 35\% terhadap derajat kesehatan. Mengingat dampak dari perilaku terhadap derajat kesehatan cukup besar, maka diperlukan berbagai upaya untuk mengubah perilaku yang tidak sehat menjadi sehat. Salah satunya melalui program Perilaku Hidup Bersih dan Sehat (PHBS) yang dicanangkan oleh DepKes RI. ${ }^{1}$

Indeks Pembangunan Kesehatan Masyarakat 2010, rata-rata persentase Perilaku Hidup Bersih dan Sehat Nasional hanya 35,68\%. Artinya hanya 35,68\% dari total warga Indonesia yang telah berperilaku hidup bersih dan sehat. Hasilnya sampai tahun 2011 tenaga kesehatan yang terlatih PHBS tingkat provinsi 100\% (30 provinsi), 76\% kabupaten/kota, 71,3\% puskesmas. Pencapaian klasifikasi III dan IV 38,89\% tatanan rumah tangga, 50\% pendidikan, $33,3 \%$ tatanan tempat kerja dan $35,3 \%$ tatanan tempat umum. ${ }^{1}$

Sekolah dipandang sebagai sebuah tempat yang strategis untuk mempromosikan kesehatan. Sekolah juga merupakan institusi pendidikan yang efektif bagi terwujudnya pendidikan kesehatan, dimana peserta didik dapat diajarkan tentang maksud perilaku sehat dan perilaku tidak sehat serta konsekuensinya sesuai dengan tingkatan usianya. ${ }^{2}$

PHBS yang diterapkan pada anak usia sekolah berhubungan dengan disiplin diri yang terdapat pada individu masing-masing anak. Kementrian kesehatan RI mengemukakan bahwa pembentukan disiplin diri merupakan suatu proses yang dimulai sejak masa anak-anak. Pendidikan disiplin merupakan proses bimbingan untuk menanamkan pola perilaku dan kebiasaan tertentu untuk membentuk sikap manusia dengan ciri-ciri tertentu, terutama untuk meningkatkan kualitas mental dan moral serta dapat meminimalkan masalah-masalah yang sering terjadi pada anak usia Sekolah Dasa. $^{2}$

Sebagaimana penelitian yang dilakukan oleh Lilis Ati Nurhayati tentang hubungan antara pengetahuan lingkungan hidup dan kecerdasan spiritual dengan perilaku hidup bersih dan sehat siswa SMPN kota Sukabumi hasil penelitian menghasilkan tiga kesimpulan yaitu : Pertama terdapat hubungan positif yang sangat signifikan antara pengetahuan tentang lingkungan hidup dengan perilaku hidup bersih dan sehat dengan koefisien korelasi ry1 sebesar 0,802 dan persamaan regresi $Y=5, .930+1,151 \mathrm{X} 1$. Kedua, terdapat hubungan positif yang sangat signifikan antara kecerdasan spiritual dengan perilaku hidup bersih dan sehat dengan koefisien korelasi ry2 sebesar 0,775 dan persamaan regresi $\mathrm{Y}=10,470+0,784 \mathrm{X} 2$. Ketiga, terdapat hubungan positif yang sangat signifikan antara pengetahuan tentang lingkungan hidup dan kecerdasan spiritual secara bersama-sama dengan perilaku hidup bersih dan sehat dengan koefisien korelasi ry12 sebesar 0,873 dan persamaan regresi $4=3,47+$ $0,74 \mathrm{X} 1+0,45 \mathrm{X} 2 .^{3}$

Data dari Puskesmas Watubelah berdasarkan laporan hasil pendataan PHBS tatanan sekolah tahun 2012 terdapat 2 sekolah yang ada di kelurahan Watubelah yaitu SDN 1 Watubelah jumlah siswa yang diperiksa 453, memelihara rambut agar bersih dan rapih 393 $(86,7 \%)$ yang tidak bersih 60 (13.3\%), memakai baju yang bersih dan rapih $388(85,7 \%)$ yang tidak bersih $65(14,3 \%)$, memelihara kuku agar selalu bersih $383(84,5 \%)$ yang tidak 70 (15,5\%), memakai sepatu bersih dan rapih 371 (81,9\%) yang tidak bersih $82(18,1 \%)$, olahraga teratur dan terukur $421(92,9 \%)$ yang tidak $32(7,1 \%)$, tidak merokok di sekolah 453 (100\%), tidak menggunakan NapZa 453 (100). Berdasarkan data tersebut jelas memperlihatkan bahwa anak usia Sekolah Dasar di SDN 1 Watubelah Kabupaten Cirebon belum memiliki kebiasaan yang menunjuk perilaku hidup bersih dan sehat. Sedangkan dari 
pihak puskesmas sudah dilakukan penyuluhan setiap tahunnya disekolah-sekolah namun hasil dari penerapannya pada siswa disekolah masih kurang. Penulis memilih kelas VI untuk dianalisa pemahamannya tentang pengetahuan perilaku hidup bersih dan sehat, karena kelas VI merupakan tingkat pendidikannya lebih tinggi dibandingkan kelas V.

Tujuan dalam penelitian ini untuk mengetahui perbedaan pengetahuan perilaku hidup bersih dan sehat sebelum dan sesudah penyuluhan pada siswa kelas VI di SDN 1 Watubelah Kabupaten Cirebon Tahun 2013.

\section{METODE PENELITIAN}

Penelitian ini menggunakan metode pra experimen design dengan pendekatan one group pretest posttest

Bagan 1 Rancangan One Group Pretest Posttest

Pretest Perlakuan Posttest

\begin{tabular}{ll}
\hline 01 & $\mathrm{X}$
\end{tabular}

Hari pertama responden diberikan kuesioner sebelum diberikan pendidikan kesehatan dalam bentuk pertanyaan sebanyak 20 pertanyaan, selanjutnya di hari ke-2 dengan responden yang sama diberikan pendidikan kesehatan terlebih dahulu, setelah itu diberikan kuesioner dalam bentuk pertanyaan yang sama. Peserta atau respondennya yaitu siswa kelas VI SD dan peneliti sendiri yang melakukan kegiatan pemberian kuesioner serta memberikan satu kali penyuluhan tentang PHBS, dengan medianya berupa gambar yang menarik serta penjelasan yang bersahabat agar siswa dapat menyerap materi yang telah disampaikan. Pada penelitian ini populasi yang diambil adalah seluruh siswa kelas VI di SDN 1 Watubelah Kabupaten Cirebon Tahun 2013 yang berjumlah 30 orang. Teknik pengambilan sampel pada penelitian ini adalah dengan menggunakan total sampling. Berdasarkan sedikitnya populasi penelitian yaitu hanya 30 orang maka sampel yang diambil juga seluruh jumlah populasi yang ada. Dalam penelitian ini menggunakan instrumen penelitian berupa kuesioner tertutup (close ended). Metode pengumpulan data menggunakan angket. Analisis Univariat disajikan dalam tabel distribusi frekuensi. Analisis Bivariat digunakan untuk membuktikan hipotesis penelitian dengan menggunakan uji $\mathrm{T}$ dependen seringkali disebut uji $\mathrm{T}$ Pair/Related atau pasangan. $^{4}$

HASIL PENELITIAN

\section{Pengetahuan Perilaku Hidup Bersih dan Sehat}

Tabel 1 Daftar Distribusi Frekuensi Pengetahuan Perilaku Hidup Bersih dan Sehat Siswa Sebelum Diberikan Penyuluhan

\begin{tabular}{cccc}
\hline No. & Kategori & Jumlah & Persentase \\
\hline 1. & Baik $(11-20)$ & 20 & $66,7 \%$ \\
2. & Kurang Baik (0-10) & 10 & $33,3 \%$ \\
\hline & Total & 30 & $100 \%$ \\
\hline
\end{tabular}


Berdasarkan tabel 1 menunjukkan bahwa pengetahuan perilaku hidup bersih dan sehat siswa sebelum diberikan penyuluhan sebagian besar responden memiliki pengetahuan baik yaitu sebanyak 20 responden $(66,7 \%)$

\section{Pengetahuan Perilaku Hidup Bersih dan Sehat Sesudah Penyuluhan}

Tabel 2 Daftar Distribusi Frekuensi Pengetahuan Perilaku Hidup Bersih dan Sehat Siswa Sesudah Diberikan Penyuluhan

\begin{tabular}{|c|c|c|c|}
\hline No & Kategori & Jumlah & Persentase \\
\hline 1 & Baik (11-20) & 27 & $90,0 \%$ \\
\hline 2 & Kurang Baik (0-10) & 3 & $10,0 \%$ \\
\hline & Total & 30 & $100 \%$ \\
\hline
\end{tabular}

Berdasarkan tabel 2 menunjukan bahwa pengetahuan perilaku hidup bersih dan sehat siswa sesudah diberikan penyuluhan yang paling banyak adalah pengetahuan yang baik yaitu sebanyak 27 responden $(90,0 \%)$.

\section{Perbedaan Pengetahuan PHBS Sebelum dan Sesudah Penyuluhan}

Tabel 3 Pengetahuan Perilaku Hidup Bersih dan Sehat Sebelum dan Sesudah Penyuluhan

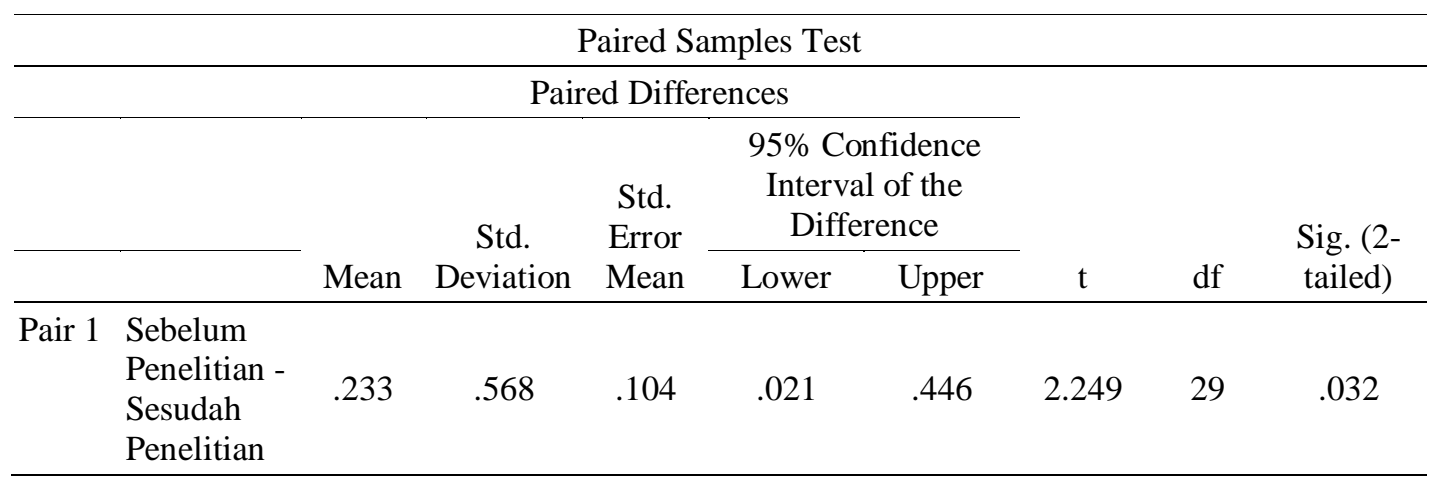

Berdasarkan tabel 3 uji statistik hasil $\mathrm{T}$ test $=2.249$ dengan derajat kepercayaan yang digunakan adalah $95 \%$ dan nilai $\alpha=0.05$ didapat $\rho$ value $=0,032$, dimana $\rho<0.05$ dapat disimpulkan bahwa ada perbedaan pengetahuan perilaku hidup bersih dan sehat sebelum dan sesudah penyuluhan pada siswa kelas VI SDN 1 Watubelah Tahun 2013.

\section{PEMBAHASAN}

\section{Pengetahuan Perilaku Hidup Bersih dan Sehat Siswa Sebelum Diberikan Penyuluhan}

Dari hasil distribusi frekuensi pengetahuan perilaku hidup bersih dan sehat sebelum diberikan penyuluhan dari 30 responden yaitu sebanyak 20 responden $(66,7 \%)$ pengetahuannya baik dan 10 responden pengetahuan kurang baik $(33,3 \%)$.

Kemudian teori yang menyatakan bahwa perilaku hidup bersih dan sehat di sekolah berarti anak sekolah harus diberdayakan agar sadar, mau dan mampu melaksanakan Perilaku Hidup Bersih dan Sehat (PHBS) di sekolah. PHBS di sekolah berarti ketersediaan sarana lingkungan sekolah yang 
sehat harus diupayakan dan menjadi urusan pemerintah kabupaten kota, serta jajarannya, khususnya sektor pendidikan kesehatan, dan lain-lain. ${ }^{6}$

\section{Pengetahuan Perilaku Hidup Bersih dan Sehat Siswa Sesudah Diberikan Penyuluhan}

Dari hasil distribusi frekuensi pengetahuan perilaku hidup bersih dan sehat sesudah diberikan penyuluhan dari 30 responden yaitu sebanyak 27 responden $(90,0 \%)$ pengetahuannya baik dan 3 responden pengetahuan kurang baik $(10,0 \%)$.

Hasil penelitian ini sejalan seperti yang dikemukakan WHO dalam Notoatmodjo (2007), salah satu starategi untuk perubahan perilaku adalah pemberian informasi guna meningkatkan pengetahuan sehingga timbul kesadaran yang pada akhirnya orang akan berperilaku sesuai dengan pengetahuannya tersebut. Salah satu upaya pemberian informasi yang dapat dilakukan adalah penyuluhan. ${ }^{6}$

Penelitian ini juga di dukung oleh teori menurut Notoatmodjo yaitu pendidikan kesehatan pada hakekatnya adalah suatu kegiatan atau usaha individu untuk menyampaikan pesan kesehatan kepada masyarakat, kelompok atau individu dapat menumbuhkan pengetahuan tentang kesehatan. Akhirnya pengetahuan tersebut diharapkan dapat berpengaruh terhadap perlakuannya. Dengan kata lain dengan adanya pendidikan tersebut dapat membawa akibat terhadap perubahan perilaku sasaran. ${ }^{6}$

\section{Perbedaan Pengetahuan Perilaku Hidup Bersih dan Sehat Sebelum dan Sesudah Diberikan Penyuluhan}

Berdasarkan hasil penelitian dapat terlihat bahwa adanya perbedaan antara pengetahuan sebelum dan sesudah dilakukan penyuluhan. Hal ini dapat disebabkan karena sesudah dilakukan penyuluhan siswa telah mampu mempersepsikan sesuatu dengan berdasar nilai yang telah dipegangnya, yang mana nilai-nilai tersebut akan diaplikasikan ke dalam perilaku.

Penelitian ini sesuai dengan penelitian yang dilakukan oleh Zul Salsala, Dkk. Tentang pengaruh penyuluhan denga metode ceramah dan diskusi terhadap peningkatan pengetahuan dan sikap anak tentang PHBS di Sekolah Dasar Negeri 065014 kelurahan Namogajah kecamatan Medan Tuntungan Tahun 2013. Hasil penelitian menunjukan bahwa terdapat peningkatan pengetahuan dan sikap pada responden akibat dari intervensi melalui penyuluhan dengan metode ceramah, Terdapat peningkatan pengetahuan dan sikap pada responden akibat dari intervensi melalui penyuluhan dengan metode diskusi. Metode penyuluhan yang paling efektif digunakan untuk meningkatkan pengetahuan dan sikap anak sekolah dasar tentang PHBS adalah melalui metode diskusi. ${ }^{7}$

Pengetahuan itu sendiri adalah hasil dari tahu dan hal ini terjadi setelah orang melakukan penginderaan terhadap sesuatu objek tertentu. Penginderaan ini terjadi melalui panca indera manusia, yakni indera penglihatan, pendengaran, penciuman, raba dan rasa dan sebagian besar pengetahuan manusia diperoleh melalui mata dan telinga. Pengetahuan atau kognitif merupakan domain yang sangat penting dalam membentuk tindakan seseorang (over behavior). ${ }^{6}$

\section{SIMPULAN}

1. Pengetahuan perilaku hidup bersih dan sehat siswa SDN 1 Watubelah Kabupaten Cirebon sebelum dilakukan penyuluhan berada pada kategori baik yaitu sebesar 66,7\%.

2. Sebagian besar Pengetahuan perilaku hidup bersih dan sehat siswa SDN 1 Watubelah Kabupaten Cirebon sesudah dilakukan penyuluhan berada pada kategori baik yaitu sebesar $90,0 \%$.

3. Terdapat perbedaan antara pengetahuan perilaku hidup bersih dan sehat sebelum dilakukan penyuluhan dengan sesudah dilakukan penyuluhan pada siswa diSDN 1 Watubelah Kabupaten Cirebon. 


\section{SARAN}

\section{Bagi Puskesmas}

Hasil penelitian ini dapat digunakan sebagai rujukan untuk penelitian dalam mengembangkan program kesehatan masyarakat dan model penyuluhan yang kreatif, khususnya menarik kemauan Anak Usia Sekolah Dasar yang terkait penerapan PHBS.

2. Bagi Peneliti Selanjutnya

Bagi peneliti selanjutnya sebagai dasar untuk melakukan penelititan lanjutan terkait dengan pengetahuan perilaku hidup bersih dan sehat pada siswa.

3. Bagi Anak Sekolah/Siswa

Dapat memberikan informasi bagi anak sekolah agar terbentuk sikap untuk sadar dan mampu melaksanakan perilaku hidup bersih dan sehat di sekolah.

\section{DAFTAR PUSTAKA}

1. Depkes RI. Peningkatan PHBS pusat promosi kesehatan. Jakarta:Depkes RI;2009

2. Depkes R I. Panduan Perilaku Hidup Bersih Dan Sehat Di Rumah Tangga. Jakarta:Pusat Promosi Kesehatan;2009

3. Lilis A. Hubungan antar pengertahuan lingkungan hidup dan kecerdasan spiritual dengan perilaku hidup bersih dan sehat siswa SMPN Kota Suka Bumi. 2010 [diakses tanggal 13 mei 2013]. Diunduh dari:http//www.digilib.uin.suka.ac.id

4. Puskesmas Watubelah. Laporan hasil pendataan PHBS tatanan sekolah 2012

5. Sugiono. Metode penelitian kuantitatif kualitatif dan R\&D. Bandung : Alfabeta : 2010

6. Notoatmodjo, Soekidjo. Kesehatan masyarakat: Ilmu dan Seni. Jakarta: Rineka Cipta. 2007

7. Zul Salasa Akbar Lubis, dkk. pengaruh penyuluhan dengan metode ceramah dan diskusi terhadap peningkatan pengetahuan dan sikap anak Tentang phbs di sekolah dasar negeri 065014 Kelurahan Namogajah kecamatan Medan tuntungan Tahun 2013 [diakses tanggal 27 agustus 2013]. Diunduh dari:http//www.jurnal.usu.ac.id/index.php 